\title{
Paleofire in the wet tropics of northeast Queensland,
} \section{Australia}

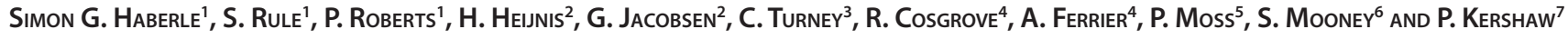 \\ ${ }^{1}$ Archaeology and Natural History, School of Culture, History and Language, College of Asia and the Pacific, Australian National University, Can- \\ berra, Australia; simon.haberle@anu.edu.au \\ ${ }^{2}$ Institute for Environmental Research, Australian Nuclear Science and Technology Organisation, Sydney, Australia; ${ }^{3}$ School of Geography, The \\ University of Exeter, UK; ${ }^{4}$ Archaeology Program, La Trobe University, Melbourne, Australia; ${ }^{5}$ School of Geography, Planning and Environmental \\ Management, The University of Queensland, Brisbane, Australia; ${ }^{6}$ School of Biological, Earth and Environmental Sciences, University of New \\ South Wales, Sydney, Australia; ${ }^{7}$ School of Geography and Environmental Science, Monash University, Melbourne, Australia
}

\section{New approaches to fire history reconstructions in Australia provide insights into climate, human and ecosystem influences on fire regimes of the past.}

Fire in wet tropical environments is often associated with deforestation and degradation of diverse and "pristine" habitats. These notions have been exacerbated by mega-fire events associated with El Niñorelated droughts in Southeast Asia and New Guinea. Forest loss in Indonesia after the intense El Niño of 1997-98 is estimated at more than 5 million hectares (Glover and Jessop, 1999) and the carbon released as a result of these fires is thought to have been equivalent to $40 \%$ of the mean annual global carbon emissions from fossil fuels for that year (Page et al., 2002). These events led to fears that repeated large fires in the future may lead to large changes in the distribution of rainforest and sclerophyll (trees and shrubs with hard leaves adapted mainly to dry climate) communities in northern Australia. There is growing recognition that a greater understanding of the role of fire in the environment is needed, and can be gained through the study of the frequency and impact of past fire events (Lynch et al., 2007; Bowman et al., 2009).

\section{Fire and Australian Rainforests}

The Wet Tropics of Far North Queensland, Australia, contain a complex and biodiverse vegetation that covers approx. 1.8 million hectares, from sea level to cool humid mountains over $1600 \mathrm{~m}$ asl. On the Atherton Tableland (see Fig. 1), a fragmented band of sub-montane rainforest is interspersed with fire-prone sclerophyll vegetation (including grasslands, open woodlands and eucalypt forests) (Hopkins et al., 1993; Hilbert et al., 2001). The boundary between rainforest and fireprone sclerophyll vegetation is buffered by wet sclerophyll forests, characterized by a sclerophyll overstorey with a rainforest and pyrophytic (fire tolerant) species underneath. The arrival of European settlers in the 1880s heralded a period of rapid rainforest clearance and burning for forestry, pastoral and agricultural purposes. Prior to this, human-lit fires were associated with Aboriginal occupation, and exploitation of the fire-prone sclero-

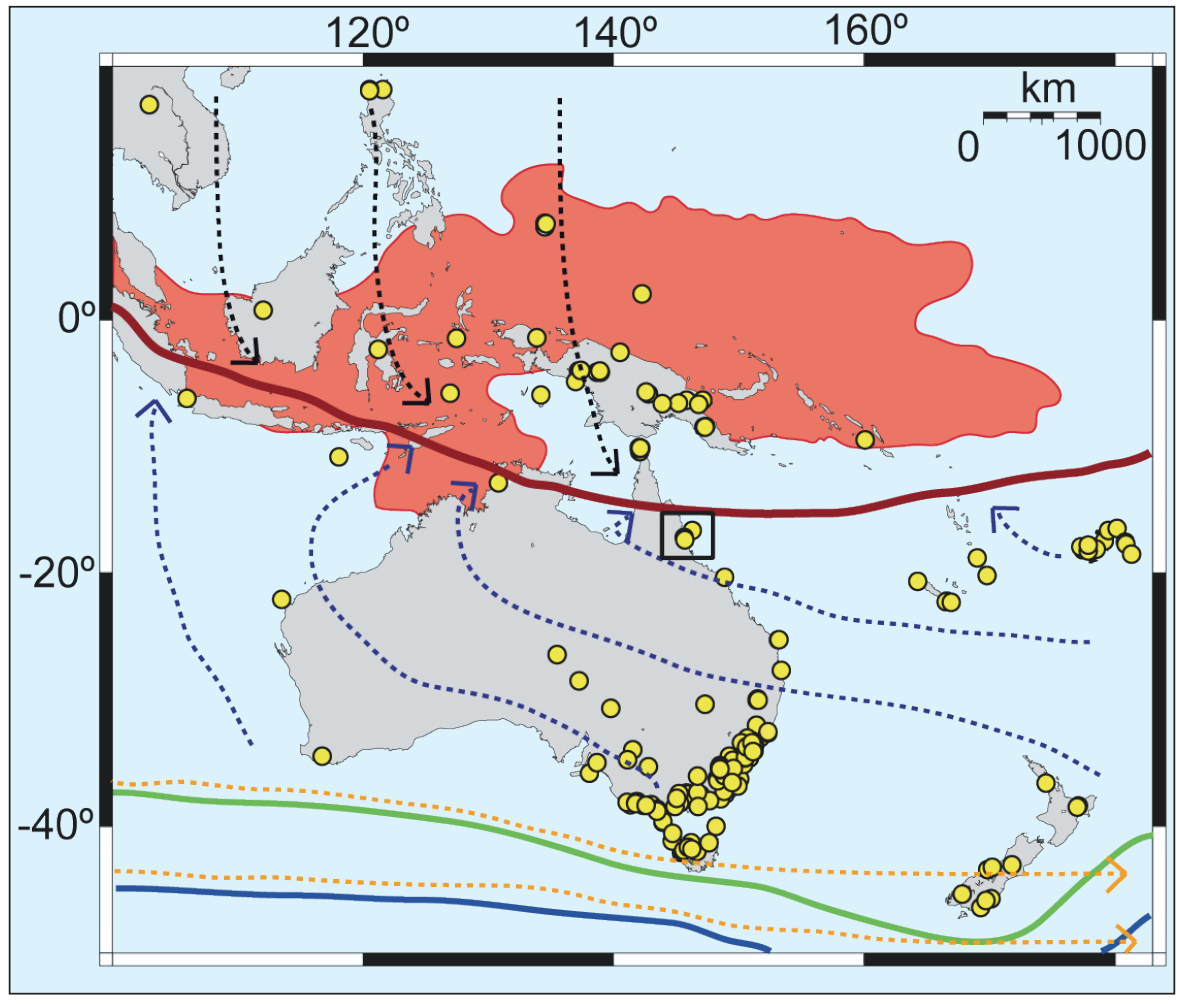

Figure 1: Location of Atherton Tablelands (black box) and paleoecological sites in Australasia that have charcoal data (yellow circles, data from databases mentioned in Data section of text). The principal atmospheric circulation affecting the Atherton Tablelands region during the austral summer, and mean annual location of oceanic water masses are also shown: Red line = Inter-Tropical Convergence Zone, green line = Sub-Tropical Front, blue line = Sub-Antarctic Front, red shaded area = western Pacific warm pool, orange dashed arrows = westerlies, black dashed arrows = Asian monsoon, blue dashed arrows = Southeast Trade winds.

phyll vegetation began as early as 30,000 years ago, although human occupation of rainforests is evident only with the period of postglacial expansion of rainforest after 8 cal ka BP (Cosgrove et al., 2007). Lightning strikes may also have been an ignition source leading to large wildfires during severe drought conditions. Whatever the source of ignition, extended droughts coupled with dry seasons strongly increased the likelihood and consequences of fire in otherwise fire-resistant rainforests of the Atherton Tableland (Marrinan et al., 2005).

Today the dominant source of precipitation in the Atherton Tableland is the Southeast Trades and occasional northwesterly monsoonal flows. Associated tropical cyclones bring high but infrequent rainfall events during the austral summer months when the intertropical convergence zone (ITCZ) is at its most southerly extent (Fig. 1). During El Niño episodes, a northward movement of the ITCZ and a northeastward migration of the South Pacific Convergence Zone result in a significant decrease in summer precipitation (typically 150-300 mm below seasonal average) over the region. This can create conditions suitable for fires to penetrate otherwise "impenetrable" or pyrophobic rainforest habitats.

Records show that fires have long been a factor in rainforest dynamics on the Atherton Tablelands (Haberle, 2005; Kershaw et al., 2007). Charcoal identified to rainforest species (Halfordia sp. and Pouteria sp.) have been dated to $0.4-0.25 \mathrm{cal}$ ka BP within soil under "pristine" rainforest vegetation (Cosgrove, 2005) suggesting that some fire events are destructive to rainforest and that rainforest species can recolonize if fire return intervals are long (multi-century). Frequent fires have led to 


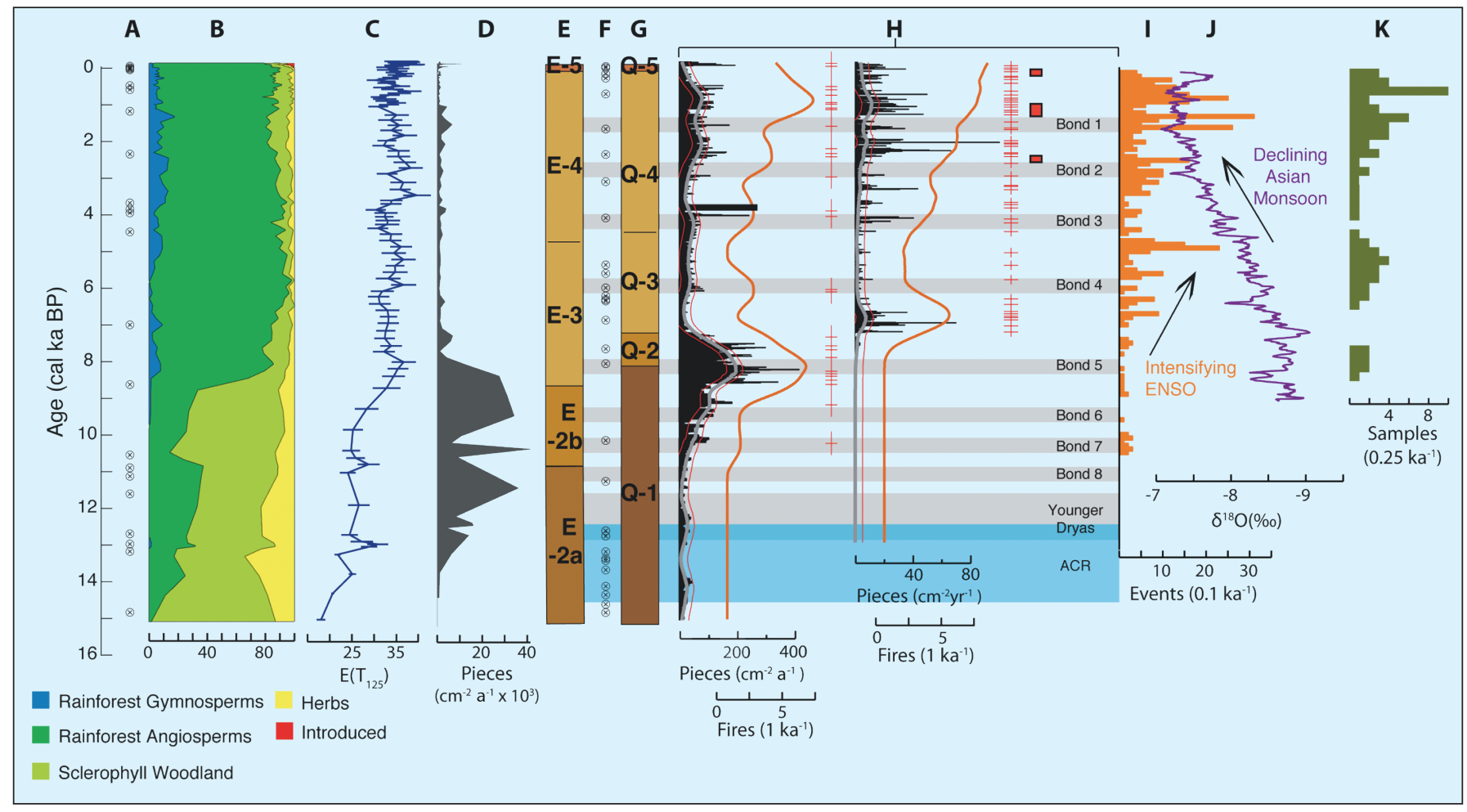

Figure 2: Selected pollen and charcoal data for Lake Euramoo and Quincan (rater. A) and F) Euramoo and Quincan ${ }^{14} \mathrm{C}$ samples, respectively. B) Euramoo pollen diagrams and (C) Euramoo palynological richness (E( $\left.T_{12}\right)=$ standardized pollen sum) plotted using Psimpoll (@ Kieth Bennett). D) Euramoo microcharcoal $(<125$ um) reflecting burning of low plant biomass during the glacial period. E) Euramoo and (G) Quincan pollen zones representing past vegetation (Kershaw, 1971; Haberle, 2005; unpublished data): Q-1 = Dry sclerophyll woodland: E-2a = Wet sclerophyll woodland (> Eucalyptus and grass) with marginal rainforest; Q-2 and E-2b= Wet sclerophyll woodland (> Casuarina) with marginal rainforest; Q-3 and E-3 = Lower montane rainforest dominated by Cunoniaceae and Urticaceae/Moraceae; Q-4 and E-4 = Sub-montane rainforest dominated by Elaeocarpaceae; Q-5 and E-5 = degraded sub-montane rainforest with European introductions. $\boldsymbol{H}$ ) Fire event reconstruction from Euramoo (left) and Quincan (right) based on raw charcoal accumulation rate (black plots) over interpolated 7-a intervals with the background signal (Lowess smoothing, gray line) and global threshold (mean Gaussian model, thin red lines). Also shown are the detected peak fire events (red +), simulated fire frequency (orange line) over 1 ka intervals (CharAnalysis, @ Philip Higuera, see Higuera et al. 2009), synchronous peak fire events (red boxes), Northern Hemisphere multi-centennial paleoclimate events (gray shaded bars; Bond et al., 2001) and the Antarctic Cold Reversal (ACR; blue shading; Blunier et al., 1997). For interpretation of possible drivers, regional climate records are shown for comparison including I) total number of strong El Niño events per century interpreted from flood deposits in Laguna Pallcacocha, Ecuador (orange bars; Moy et al., 2002), J) Past precipitation in Chin a from the Dongge Cave speleothem $\delta^{18} \mathrm{O}$ record (purple line; Wang et al., 2005), and $\boldsymbol{K}$ ) Radiocarbon dates associated with archaeological sites in the Wet Tropics region (number of ${ }^{14} \mathrm{C}$ dates/250-a windows) from Cosgrove et al., 2007).

long-term changes in rainforest communities, which may take hundreds of years to recover, or result in a rapid transition to an alternative stable state (Warman and Moles, 2009). Pollen records from Lake Euramoo (718 $\mathrm{m}$ asl, $17^{\circ} 09^{\prime} 30^{\prime \prime} \mathrm{S}, 145^{\circ} 37^{\prime} 46^{\prime \prime} \mathrm{E}$ ) and Lynch's Crater (760 m asl, $17^{\circ} 21^{\prime} 56^{\prime \prime} \mathrm{S}$, $\left.145^{\circ} 41^{\prime} 10^{\prime \prime} \mathrm{E}\right)$ suggest that shifts from rainforest to sclerophyll and vice versa occurred in only a few centuries as exemplified by major shifts between dominance of sclerophyll to rainforest vegetation approximately $8 \mathrm{cal}$ ka BP, $38 \mathrm{cal}$ ka BP, 132 ka and $222 \mathrm{ka}$; each shift is accompanied by increased charcoal just prior to rainforest dominance (Haberle, 2005; Kershaw et al., 2007).

Two decadal charcoal records from Lake Euramoo and Quincan Crater (16 $\mathrm{km}$ to the southwest of Lake Euramoo at $790 \mathrm{~m}$ asl, $\left.17^{\circ} 18^{\prime} 07^{\prime \prime} \mathrm{S}, 145^{\circ} 34^{\prime} 53^{\prime \prime} \mathrm{E}\right)$, provide a better understanding of fire's on the Atherton Tablelands. Charcoal particle concentration per unit volume was determined following methods of Whitlock and Larson (2001). The size fraction of charcoal analyzed here was of sufficient size to provide an indicator of local burning (assumed to be within $\sim 200 \mathrm{~m}$ of the sites). This is in contrast to microscopic charcoal particles counted on pollen slides that may be derived from many kilometers from the sampling site, and thus a good indicator for regional fire activity.

The Lake Euramoo record shows that past fire-event frequencies in rainforest environments fluctuated between 2-5 events per 1 ka (Fig. 2). Macroscopic charcoal preservation was poor in glacial clayey sediments and statistically reliable charcoal concentrations only occurred after $15 \mathrm{cal}$ ka BP at Lake Euramoo and 10 cal ka BP at Quincan Crater. Micro-charcoal was preserved and in much higher concentration during the glacial period compared to the Holocene, perhaps reflecting continued burning of low plant biomass (open sclerophyll woodland dominated by Casuarina and Eucalyptus with a grass understorey). Peak fire-event frequency at ca. 8 cal ka BP was associated with a rapid transition from sclerophyll to rainforest. Increasing plant biomass produced greater quantities of charcoal as rainforest species invaded Eucalyptus (particularly E. intermedia comp.) woodland and thus high fireevent frequencies, typical of the fire prone wet sclerophyll forests of today, occurred. Despite rising fire-event frequencies in the late Holocene (from 2 to 5 events per $1 \mathrm{ka}$ ), the biodiversity of rainforest at Lake Euramoo has remained relatively stable for the last $8 \mathrm{ka}$.

\section{Fire Frequency Change}

What are the drivers for changes in fireevent frequency in the wet tropics of northern Australia? The new core from Quincan Crater (Fig. 2) shows the post-glacial rapid expansion of rainforest approximately 1.5 ka later, at 7 cal ka BP (Kershaw, 1971 and unpublished data) than at Lake Euramoo (Haberle, 2005). This difference represents a rate of rainforest expansion of about $3 \mathrm{~m} / \mathrm{a}$, which is three times greater than that recorded in modern rainforest expansion surveys under conditions of reduced burning and increased atmospheric $\mathrm{CO}_{2}(\sim 1 \mathrm{~m} / \mathrm{a}$; Adam, 1992). The delayed nature of the transition from a mosaic of sclerophyll and rainforest to rainforest dominance at Lake Euramoo (15-8.7 cal ka BP) compared with Quincan Crater ( 7.2$6.8 \mathrm{cal} \mathrm{ka} \mathrm{BP)} \mathrm{may} \mathrm{relate} \mathrm{to} \mathrm{the} \mathrm{proxim-}$ ity of Lake Euramoo to glacial rainforest refugia and the relatively rapid spread of rainforest eastward across the Atherton Tableland after 8.7 cal ka BP.

Low fire-event frequencies characterize the mid-Holocene period when warm 
temperate rainforest covered the region. A combination of low inter-annual climate variability (ENSO-related), declining strength of the Asian monsoon, and low intensity of Aboriginal occupation in the rainforests likely caused low charcoal quantities and fire-event frequencies. It was not until around 4 cal ka BP that charcoal quantities and fire-event frequencies rose across the region, peaking in the last 2 ka. Holocene El Niño activity has been highest in the last $2 \mathrm{ka}$ and may have been a significant cause of drought and greater potential fire ignition over this time. This period also coincides with evidence for increased Aboriginal site occupation and the adoption of more complex foodextraction strategies and intensive use of rainforest resources (Turney and Hobbs, 2006; Cosgrove et al., 2007).

\section{Concluding remarks}

The comparison of charcoal records with climate and human impact proxies in the Wet Tropics of Australia reveals the complexity inherent in fire dynamics through time. There are corresponding peaks in fire-event frequencies and millennialscale climate changes in the North Atlan- tic (Bond et al., 2001; Turney et al., 2005) and regional climate drivers (El Niño activity) that may have influenced fire ignition in the wet tropic rainforests of Australia through the Holocene. However, no single driver can explain past fire patterns and many events may be the result of multiple drivers (climate-vegetation-people) interacting on differing temporal and spatial scales. It also remains unclear whether or not Northern Hemisphere millennialscale climate changes had an impact on the Australian tropics (Turney et al., 2004). In Australia, current severe drought and plant mortality are increasing fire hazard and raising concerns about the trajectory of post-fire vegetation change and future fire regimes (Lynch et al., 2007; Bowman et al., 2009). Understanding the interaction between multiple drivers of fire and fire-events from the past will be critical information for managing fire regimes in Australia in the future.

\section{Data}

The Lake Euramoo and Quincan Crater data are available upon request from the first author. Data shown in Figure 1 are from the Indo-Pacific Pollen Database http://palaeoworks.anu.edu. au/databases.html and the Global Palaeofire
Database http://www.bridge.bris.ac.uk/projects/ QUEST_IGBP_Global_Palaeofire_WG/index.html).

\section{Acknowledgements}

This work is financially supported by the Australian Research Council (Grants DP0986579, DP0664898 and DP0210363) and Australian Institute for Nuclear Science and Engineering (Grant ANGRA00060), and the Australian Nuclear Science and Technology Organisation.

\section{References}

Cosgrove, R., Field, J. and Ferrier, A., 2007: The archaeology of Australia's tropical rainforests, Palaeogeography, Palaeodlimatology, Palaeoecology, 251: 150-173.

Haberle, S.G., 2005: A 23,000-yr pollen record from Lake Euramoo, Wet Tropics of NE Queensland, Australia, Quaternary Research, 64 343-356

Higuera, P.E., Brubaker, L.B., Anderson, P.M., Hu, F.S. and Brown, T.A., 2009: Vegetation mediated the impacts of postglacial climatic change on fire regimes in the south-central Brooks Range, Alaska, Ecological Monographs, 79: 201-219.

Kershaw, A.P., Bretherton, S.C. and van der Kaars, S., 2007: A complete pollen record of the last 230 ka from Lynch's Crater, north-eastern Australia, Palaeogeography, Palaeoclimatology, Palaeoecology, 251: 23-45.

Lynch, A.H., Beringer, J., Kershaw, A.P., Marshall, A., Mooney, S., Tapper, N., Turney, C. and Van Der Kaars, S., 2007: Using the paleorecord to evaluate climate and fire interactions in Australia, Annual Review of Earth and Planetary Sciences, 35: 215-39.

For full references please consult:

http://www.pages-igbp.org/products/newsletters/ref2010_2.html

\title{
Humans and fire: Consequences of anthropogenic burning during the past 2 ka
}

\author{
Jennifer R. Marlon ${ }^{1}$, Q. Cui ${ }^{2}$, M.-J. Gaillard ${ }^{2}$, D. McWethy ${ }^{3}$ and M. Walsh ${ }^{1}$ \\ 'University of Oregon, Eugene, USA; jmarlon@uoregon.edu \\ LLinnaeus University, Kalmar, Sweden; ${ }^{3}$ Montana State University, Bozeman, USA
}

\section{Holocene sedimentary charcoal records document human influences on biomass burning around the world, with global-scale consequences in the past two centuries.}

A global network of sedimentary charcoal records (Fig. 1a; Power et al., 2008) has shown that trends in biomass burning that were long controlled by climate (including $\mathrm{CO}_{2}$ changes) have now come to be driven primarily by people (Fig. 2a-d; Marlon et al., 2008). Three case studies from western North America, New Zealand and Europe demonstrate the spatiotemporal variability of human impacts on fire regimes and vegetation and illustrate why local impacts do not aggregate to distinct broadscale signals until the very recent past.

\section{Western North America}

In the Pacific Northwest, paleoecological records illustrate a wide range of climatic and human influences on fire regimes during the past $2 \mathrm{ka}$. For example, at Battle Ground Lake (conifer forest; Washington State), fire occurrence tracked climatic changes prior to Euro-American settle- ment (ca. AD 1830), most notably showing high fire activity during the Medieval Climate Anomaly (MCA; ca. AD 950-1250) and almost no fires during the Little Ice Age (LIA; ca. AD 1450-1850) (Fig. 1b; Walsh et al., 2008)-a pattern characteristic of many other sites in western North America (Marlon et al., 2006). These shifts seemingly occurred in the absence of major vegetation changes, suggesting little association with Native American landuse (fire was used to create more open and resource-rich landscapes). Following Euro-American settlement, fire occurrence was more clearly influenced by human activity, with a large-magnitude fire event in AD 1902 and little to no fire in the last 100 years. In contrast, fire activity at Lake Oswego (oak woodland; Oregon) was likely the result of anthropogenic burning modulated by regional climate variability. Fire activity generally increased ca. AD 0-1000 despite cooling summer temperatures, suggesting land-use intensification by Native Americans (Fig. 1c) (Walsh et al., in press). By approximately AD 1000, higher fire activity, possibly aided by warmer drier conditions during the MCA, forced a sharp decline in forest cover near the site and an increase in grasses and other disturbancetolerant taxa. Frequent burning continued until the onset of the LIA (ca. AD 1450), at which time fires decreased and forest cover subsequently increased. The timing of this regime shift could be associated with the collapse of Native American populations following Euro-American contact (Boyd, 1999) or reduced ignitions and fireconducive weather during the LIA. Little to no fire activity has occurred at Lake Oswego in the last 300 years. Thus, the extent of human impacts on fire regimes in the Pacific Northwest appears closely linked to the spatial configuration of vegetation 